\title{
Overexpression of homeodomain- interacting protein kinase 2 (HIPK2) attenuates sepsis-mediated liver injury by restoring autophagy
}

Zhengyu Jiang ${ }^{1}$, Lulong Bo ${ }^{1}$, Yan Meng ${ }^{1}$, Chen Wang ${ }^{2}$, Tianxing Chen ${ }^{3,4}$, Changli Wang ${ }^{1}$, Xiya Yu ${ }^{1}$ and Xiaoming Deng ${ }^{1}$

\begin{abstract}
Sepsis is the leading cause of death in intensive care units worldwide. Autophagy has recently been shown to protect against sepsis-induced liver injury. Here, we investigated the roles of homeodomain-interacting protein kinase 2 (HIPK2) in the molecular mechanism of sepsis-induced liver injury. HIPK2 expression was reduced in sepsis-induced liver injury, and HIPK2 overexpression increased the survival rate and improved caecal ligation and puncture (CLP)induced liver injury by reducing serum and liver aspartate transaminase (AST), alanine transaminase (ALT), and alkaline phosphatase (ALP) levels in mice with sepsis. HIPK2 overexpression significantly decreased CLP-induced release of inflammatory cytokines into the serum and attenuated oxidative stress-associated indicators in mice with CLP-induced liver injury, whereas HIPK2 knockdown produced the opposite results, suggesting that HIPK2 is a negative regulator of sepsis. Furthermore, HIPK2 overexpression inhibited lipopolysaccharide (LPS)-induced apoptosis of primary hepatocytes, increased the autophagic flux, and restored both autophagosome and autolysosome formation in the livers of CLP-induced mice by suppressing calpain signalling. Importantly, HIPK2 overexpression reduced the elevated cytosolic $\mathrm{Ca}^{2+}$ concentration in LPS-treated primary hepatocytes by interacting with calpain 1 and calmodulin. Finally, several anti-inflammatory drugs, including resveratrol, aspirin, vitamin E and ursolic acid, significantly increased the levels of the HIPK2 mRNA and protein by modulating promoter activity and the 3'-UTR stability of the HIPK2 gene. In conclusion, HIPK2 overexpression may improve sepsis-induced liver injury by restoring autophagy and thus might be a promising target for the clinical treatment of sepsis.
\end{abstract}

\section{Introduction}

Sepsis has been considered the leading cause of death in intensive care units worldwide $^{1}$. Survivors of sepsis showed higher readmission rates and more severe

\footnotetext{
Correspondence: Xiya Yu (yuxiyash@163.com) or

Xiaoming Deng (deng_x@yahoo.com)

${ }^{1}$ Faculty of Anesthesiology, Changhai Hospital, Second Military Medical University, Shanghai 200433, China

${ }^{2}$ Department of Cell Biology, School of Basic Medicine, Second Military Medical University, Shanghai 200433, China

Full list of author information is available at the end of the article.

These authors contributed equally: Zhengyu Jiang, Lulong Bo

Edited by B. Zhivotovsky
}

pathological courses than patients without sepsis ${ }^{1}$. The 2016 definition of sepsis (known as Sepsis-3) has acknowledged the importance of organ dysfunction/failure. Based on the sequential organ failure assessment score, organ failure has been considered an essential component required to diagnose sepsis ${ }^{2}$. The liver plays an essential role in immunological homeostasis and metabolism ${ }^{3}$. Liver dysfunction has been considered an early indicator of a poor prognosis of sepsis ${ }^{4}$, and strategies designed to restore liver function result in a better prognosis and outcome in patients with sepsis ${ }^{5}$. Initially,

\section{(c) The Author(s) 2018}

(c) (i) Open Access This article is licensed under a Creative Commons Attribution 4.0 International License, which permits use, sharing, adaptation, distribution and reproduction c. in any medium or format, as long as you give appropriate credit to the original author(s) and the source, provide a link to the Creative Commons license, and indicate if changes were made. The images or other third party material in this article are included in the article's Creative Commons license, unless indicated otherwise in a credit line to the material. If material is not included in the article's Creative Commons license and your intended use is not permitted by statutory regulation or exceeds the permitted use, you will need to obtain permission directly from the copyright holder. To view a copy of this license, visit http://creativecommons.org/licenses/by/4.0/. 
sepsis-induced liver dysfunction is induced by multiple pathogenic factors ${ }^{6}$, including lipopolysaccharide (LPS), inflammatory factors, or pathogens ${ }^{5,7-9}$. The roles of complex reactions and substances, such as reactive oxygen species (ROS), nitrogen species (RNS), inflammation, and apoptosis ${ }^{10-12}$, as well as alterations in hepatocytes, such as autophagy and apoptosis, in the progression of sepsis have been widely investigated ${ }^{8,9,13,14}$.

Autophagy is a conserved and catabolic process in which proteins and organelles are isolated by a doublemembrane vesicle and targeted to the lysosome for proteolytic degradation ${ }^{15}$. Upregulation of autophagy attenuates the inflammatory response and improves the survival rate by reducing organ dysfunction ${ }^{16}$, whereas inhibition of autophagy has been reported to result in increased mortality by exacerbating injury induced by multiple factors and depleting immune cells in patients with sepsis ${ }^{17,18}$. Thus, autophagy might be a promising target for managing sepsis. Recent studies using a caecal ligation and puncture model (CLP) to induce sepsis have observed a significant increase in autophagy in the mouse liver that was identical to clinical patients ${ }^{19,20}$, and the activation of autophagy may be enhanced by genipin and growth arrest and DNA damage inducible protein 34 (GADD34), which exert protective effects against sepsis $^{13,14}$. Importantly, inhibition of mTOR exerts protective effects against acute kidney injury in mice with endotoxaemia ${ }^{21}$. A loss of $\mathrm{Ca}^{2+}$ homeostasis affects the activity of the $\mathrm{Ca}^{2+}$-dependent cysteine protease calpain, leading to organ injury ${ }^{22}$. The calpain system suppresses the progression of autophagy by directly cleaving Atg proteins throughout the autophagy course ${ }^{23,24}$. Furthermore, activities and levels of calpain proteins are increased in CLP-induced sepsis models, indicating that calpains may inhibit autophagy in sepsis ${ }^{25}$. In this study, we focused on the autophagic flux and its related signalling pathways in CLP-induced sepsis.

Homeodomain-interacting protein kinase 2 (HIPK2) is a serine/threonine kinase that is mainly located in the nucleus $^{26}$. HIPK2 is a potential tumour suppressor, as it promotes apoptosis in response to chemotherapeutic drugs and radiation, mainly by phosphorylating $\mathrm{p} 53^{27,28}$. HIPK2 also protects cells against genome instability by enhancing DNA damage repair signalling ${ }^{29}$. Nevertheless, HIPK2 can also support tumour progression. HIPK2 is significantly overexpressed in cervical cancer ${ }^{30}$, pilocytic astrocytoma $^{31}$, and ovarian and prostate tumours compared with normal samples ${ }^{31,32}$, and it is also overexpressed in aggressive meningiomas compared with benign meningiomas ${ }^{33}$. Furthermore, HIPK2 functionally interacts with $\mathrm{NRF}^{34}$, a transcription factor involved in protecting the liver and autophagy ${ }^{35-40}$. However, the precise effects of HIPK2 on autophagy and sepsis-induced liver injury remain unclear. As CLP animal model is regarded as a better choice to simulate sepsis development in the clinic $^{19,20,41}$, we investigated the molecular mechanisms underlying the protective effect of HIPK2 on CLP-induced sepsis, devoting our attention to the mechanisms regulating autophagy.

\section{Materials and methods}

\section{Animals and adenovirus preparation}

Eight-week-old C57 BL/6 male mice weighing $\sim 20.8 \mathrm{~g}$ each were used in this study. All mice were purchased from the Experimental Animal Centre of the Second Military Medical University (Shanghai, China). Animals were housed in a specific pathogen-free room in cages with sawdust bedding at a temperature of $\sim 25^{\circ} \mathrm{C}$, a relative humidity of $\sim 50 \%, 12 \mathrm{~h}$ light/day, and free access to water and food. All procedures performed on the animals used in this study were approved by the Animal Care and Protection Committee of the Second Military Medical University. The authors confirm that the animals received human care, and all animal experiments were performed in accordance with the relevant guidelines and regulations.

Recombinant adenoviruses expressing mouse HIPK2 (Ad-HIPK2) and an shRNA targeting HIPK2 (AdshHIPK2) were generated using the pAd-Easy system (Invitrogen, California, USA). The Ad-vector or Ad-NC was used as the negative control. We inserted a mouse albumin promoter in the adenovirus system to exclusively express the adenovirus in the liver. The obtained viruses were diluted with phosphate-buffered saline (PBS) and injected at a concentration of $2 \times 10^{9}$ plaque-forming units into each mouse via the tail vein. All other chemicals were purchased from Sigma.

\section{Experimental design and CLP model of sepsis}

In this study, sepsis was induced by performing a CLP as reported previously ${ }^{42}$. Mice were randomly divided into several groups: the control (sham) group and the CLPinduced group were pretreated with Ad-vector or Ad-NC, Ad-HIPK2, or Ad-shHIPK2 (30 mice for each group), and $2 \times 10^{9}$ plaque-forming units were injected into each mouse every 12 days. The CLP surgery was performed on the fifth day after the adenovirus injection. Bafilomycin A ( $10 \mathrm{mg} / \mathrm{kg}$ per day), chloroquine $(50 \mathrm{mg} / \mathrm{kg}$ per day) or rapamycin $(1 \mathrm{mg} / \mathrm{kg}$ per day) was administered $2 \mathrm{~h}$ prior to CLP. The liver and serum were obtained $16 \mathrm{~h}$ after CLP-induced sepsis for further studies. During the CLP process, the mice were anaesthetized with sevoflurane, and then a midline abdominal incision was performed. The caecum was ligated at one-half of the distal terminal and was perforated to trigger bacterial peritonitis. Next, the abdominal wall was sutured in two layers and subcutaneously injected with $1 \mathrm{~mL}$ of a $0.9 \%$ sodium chloride solution for fluid resuscitation. A laparotomy and bowel 
operation without ligation and perforation were performed on the mice in the control (sham) group. The chemicals used to establish the model were purchased from Sigma.

\section{Analyses of liver function}

As indicators of liver function, serum, and liver levels of glutathione (GSH), alanine transaminase (ALT), alkaline phosphatase (ALP), and aspartate transaminase (AST) were analysed by employing biochemical kits from Nanjing Jiancheng Bioengineering Institute (Nanjing, China).

\section{Analyses of $\mathrm{H}_{2} \mathrm{O}_{2}$ and $\mathrm{O}^{-}{ }_{2}$ production and ROS levels in the mouse liver}

Hepatic levels of $\mathrm{O}^{-}{ }_{2}$ were measured using the chemiluminescence method ${ }^{43}$. First, the mouse liver tissues were weighed and homogenized in $\mathrm{pH} 7.4$ lysis buffer containing $10 \mathrm{mM}$ ethylenediaminetetraacetic acid (EDTA) and $20 \mathrm{mM}$ 4-(2-hydroxyethyl)-1-piperazineethanesulfonic acid (HEPES). Samples were centrifuged at $1000 \mathrm{~g}$ for $10 \mathrm{~min}$. Then, an aliquot of each sample was incubated with Krebs-HEPES buffer, pH 7.4, containing $5 \mathrm{mM}$ lucigenin (Sigma, Shanghai, China) for $\sim 2$ min at $37^{\circ} \mathrm{C}$. Next, light emission data were obtained using a M200 PRO multifunctional microplate reader (TECAN, Switzerland), and the results are reported as the mean light units $\mathrm{min} / \mathrm{mg}$ protein. Levels of $\mathrm{O}^{-}{ }_{2}$ were measured by adding superoxide dismutase (SOD) $(350 \mathrm{U} / \mathrm{mL})$ to the medium according to the manufacturer's instruction (Nanjing Jiancheng Bioengineering Institute, Nanjing, China). In addition, liver tissues were homogenized in normal saline, and the samples were treated with an equal volume of cold methanol for $60 \mathrm{~min}$ in the $4{ }^{\circ} \mathrm{C}$ icebox. Then, samples were centrifuged for at $10,000 \mathrm{~g}$ for $30 \mathrm{~min}$, and we obtained the supernatant to measure $\mathrm{H}_{2} \mathrm{O}_{2}$ levels using biochemical kits (Nanjing Jiancheng Bioengineering Institute, Nanjing, China). Protein concentrations were measured using the Bradford method, and bovine serum albumin (BSA) was employed as the standard.

\section{ELISAs for the determination of IL-1 $\beta$, TNF- $\alpha$, and IL-16 levels}

The weighed liver tissues were added to a cold PBS buffer (pH 7.0) containing $0.002 \%$ sodium azide, $0.1 \mathrm{mg} / \mathrm{mL}$ soybean trypsin inhibitor, $2 \mathrm{mM}$ phenylmethylsulfonyl fluoride, $10 \mathrm{nM}$ EDTA, and $1.0 \mathrm{mg} / \mathrm{mL}$ BSA. The tissues were homogenated, and samples were then incubated for $2 \mathrm{~h}$ in a $4{ }^{\circ} \mathrm{C}$ refrigerator. For further assays, the supernatants were collected by centrifugation at $12,000 \mathrm{~g}$ for $10 \mathrm{~min}$. IL- $1 \beta$, TNF- $\alpha$, and IL-16 levels in the supernatant of serum and liver samples were measured using ELISA kits (R\&D Systems, Shanghai, China).

\section{Haematoxylin-eosin (H \& E) and immunohistochemical (IHC) staining}

Mouse liver tissues were fixed with $10 \%$ formalin, and the fixed specimens were processed into paraffin blocks, sectioned $(5 \mu \mathrm{m})$, and stained with $\mathrm{H} \& \mathrm{E}$ for the histological analysis using standard protocols ${ }^{44}$.

Liver sections were subjected to dewaxing with xylene and dehydration in a graded ethanol series. Sections were incubated with $3 \% \mathrm{H}_{2} \mathrm{O}_{2}$ for $10 \mathrm{~min}$ to block the activity of endogenous peroxidases. Then, sections were heated to $100^{\circ} \mathrm{C}$ in $0.1 \mathrm{M}$ citrate buffer (pH 6.0) for $30 \mathrm{~min}$ for antigen retrieval. These liver tissues were incubated with anti-LC3-II and anti-LAMP-2 antibodies overnight at $4{ }^{\circ} \mathrm{C}$. Next, the tissues were incubated with horseradish peroxidase-conjugated anti-rabbit or anti-mouse IgG secondary antibodies (Envision kit, Dako, Denmark) according to the manufacturer's instructions. Finally, these sections were stained with haematoxylin. The stained sections were photographed with a Carl Zeiss microscope (Axio Observer A1, Jena, Germany). The semi-quantitative analysis was performed by two investigators who were blinded to the experimental design; these investigators measured the optical density using Image software ${ }^{45}$.

\section{Reverse transcription-polymerase chain reaction (RT-PCR)}

RT-PCR and quantitative real-time PCR (Q-PCR) were performed as previously described ${ }^{46}$. Total RNA was extracted from liver tissues using TRIZOL reagent from Thermo Fisher Scientific (Waltham, MA, USA). The complementary DNA templates were obtained by reverse transcription in a $10 \mu \mathrm{L}$ reaction containing $1 \mu \mathrm{g}$ of total RNA, oligo (dT) primers, and a reverse transcription premix. QPCR was performed with the SYBR green PCR system in an ABI 7500 thermal cycler (Thermo Fisher Scientific, Waltham, MA, USA). The SYBR green reagents were also purchased from Thermo Fisher Scientific. The following cycling conditions were used: $95^{\circ} \mathrm{C}$ for $3 \mathrm{~min}$ followed by 40 cycles of denaturation at $95^{\circ} \mathrm{C}$ for $10 \mathrm{~s}$, annealing at $60^{\circ} \mathrm{C}$ for $5 \mathrm{~s}$, and extension at $72{ }^{\circ} \mathrm{C}$ for $10 \mathrm{~s}$. The mRNA levels were normalized to the level of the $\beta$-actin mRNA, which was used as an internal control. The primers were: glyceraldehyde 3-phosphate dehydrogenase (GAPDH), sense, 5' CATTCAAGACCGGACAGAGG-3', antisense, 5'-ACATACTGCACACCAGCATCACC-3'; HIPK2, sense, 5'CCAGGC CTGCTTGCTCAG-3', antisense, 5'-TGTACAGATGTGTGGGTGGC-3'. Finally, we determined the relative mRNA levels using the $2^{-\Delta \Delta \mathrm{Ct}}$ method, and GAPDH was used as an internal control.

\section{Immunoblot analysis}

Liver tissues or cells were lysed in radioimmunoprecipitation assay buffer (1 mM EDTA, $\mathrm{pH} 8.0$, $50 \mathrm{mM}$ Tris- $\mathrm{HCl}, \mathrm{pH} 8.0,2 \%$ sodium dodecyl sulfate, and $5 \mathrm{mM}$ dithiothreitol), and protein concentrations were 
determined using a bicinchoninic acid assay (Beyotime Inc., Shanghai, China). The total protein samples $(\sim 30 \mu \mathrm{g})$ were separated on an sodium dodecyl sulfate polyacrylamide gel electrophoresis gel, transferred to PVDF (polyvinylidene fluoride) membranes (Invitrogen, California, USA), and blocked with 5\% non-fat dry milk in PBST (phosphate-buffered saline with Tween), pH 7.5. Membranes were immunoblotted with primary antibodies for $4 \mathrm{~h}$ or overnight at $4{ }^{\circ} \mathrm{C}$ and then incubated with horseradish peroxidase-conjugated secondary antibodies. The anti-HIPK2 (\#5091), anti-NRF2 (\#12721), anti-NQO1 (\#62262), anti-GAPDH (\#5174), anti-p62 (\#88588), Beclin-1 (\#3738), Atg3 (\#3415), Atg7 (\#2631), LAMP-2 (\#49067), Rab7 (\#2094), cathepsin B (\#3373), anti-mTOR (\#2972), anti-phospho-mTOR (Ser2448) (\#2971), anti-4EBP1 (\#9452), anti-phospho-4E-BP1 (Ser65) (174A9) (\#9456), anti-p70 S6 kinase (\#9202), and antiphosphoplus p70 S6 kinase (Thr389) (\#9234) antibodies were purchased from Cell Signalling Technology (MA, USA). The anti-calpain 1 (NBP1-88205), anti-calpain 2 (NBP1-15675), anti-Atg5 (NB110-53818), anti-LC3-II (NBP1-19167), anti-calmodulin, and other antibodies were purchased from Novus Biologicals (CO, USA). The horseradish peroxidase-conjected secondary antibodies were all purchased from Cell Signalling Technology (MA, USA). Protein bands were detected with an enhanced chemiluminescence kit (Pierce, Rockford, USA). The corresponding semi-quantitative analysis was performed by measuring the optical density using ImageJ software, and GAPDH was used as an internal control.

\section{Isolation of primary hepatocytes}

Mouse primary hepatocytes were isolated as previously described $^{47}$. C57 BL/6 mice were anaesthetized with $1 \%$ pelltobarbitalum natricum (Amresco, USA). The mice underwent surgical dissection, the hepatic portal veins were washed to remove the blood, and a collagenase (Sigma-Aldrich, USA) perfusion was performed. The livers were immediately moved to a sterile $10-\mathrm{cm}$ cell culture dishes for mincing before the hepatocytes were dispersed by aspiration with a large-bore pipette; the hepatocytes were then filtered through a 70- $\mu \mathrm{m}$ membrane (Millipore, USA) to remove tissue debris. After two washes with cold Dulbecco's Modified Eagle's Medium (DMEM) and centrifugation at $50 \mathrm{~g}$ for $4 \mathrm{~min}$ at $4{ }^{\circ} \mathrm{C}$, the isolated hepatocytes were seeded in 6 -cm dishes containing DMEM supplemented with $10 \%$ fetal bovine serum (FBS) (both from Invitrogen, USA) at a density of $1 \times 10^{7}$ cells/dish. The medium was changed $6 \mathrm{~h}$ after seeding.

\section{Determination of primary hepatocyte apoptosis using flow cytometry}

Apoptotic cells were analysed using an annexin Vfluorescein isothiocyanate (FITC)/propidium iodide (PI) apoptosis detection kit (Beyotime, Shanghai, China). The primary hepatocytes were first isolated from the mouse liver using a previously described procedure ${ }^{48}$. Then, cells were seeded in plates and cultured overnight in DMEM supplemented with $10 \%$ FBS. Hepatocytes were transfected with Ad-HIPK2 or Ad-vector $\left(2 \times 10^{3}\right.$ plaqueforming units per well) for $16 \mathrm{~h}$, followed by an incubation with $0.5 \mu \mathrm{g} / \mathrm{mL}$ LPS for another $12 \mathrm{~h}$. Cells were harvested and centrifuged at $250 \mathrm{~g}$ for $5 \mathrm{~min}$ at $4{ }^{\circ} \mathrm{C}$ and resuspended in cold binding buffer (10 mM HEPES buffer, $\mathrm{pH} 7.4,5$ $\mathrm{mM} \mathrm{KCl}, 150 \mathrm{mM} \mathrm{NaCl}, 1.8 \mathrm{mM} \mathrm{CaCl}$, and $1 \mathrm{mM}$ $\mathrm{MgCl}_{2}$ ). Next, hepatocytes were stained with FITClabelled $25 \mathrm{ng} / \mathrm{mL}$ FITC-labelled annexin V in the dark for $40 \mathrm{~min}$, followed by an incubation with $50 \mathrm{ng} / \mathrm{mL}$ propidium iodide for $5 \mathrm{~min}$. Samples were analysed with a Becton Dickinson flow cytometer (USA). The results were analysed with flow cytometry software. In the present study, apoptotic cells were stained with annexin $V$ but not PI. Hepatocytes stained with both annexin V and PI were considered necrotic or late apoptotic cells.

\section{Measurement of cytosolic $\mathrm{Ca}^{2+}$ levels by flow cytometry}

Cytosolic $\mathrm{Ca}^{2+}$ levels were measured by flow cytometry using previously described procedures ${ }^{49}$. First, the isolated primary hepatocytes were seeded in a six-well plate and grown to $50 \%$ confluence before the application of the indicated treatment. After $12 \mathrm{~h}$ of the adenovirus infection, cells were treated with $1 \mu \mathrm{g} / \mathrm{mL}$ LPS for another $12 \mathrm{~h}$. Then, samples were washed and stained with $5 \mu \mathrm{M}$ Fluo- 4 $\mathrm{AM}$ according to the manufacturer's instructions (Invitrogen, CA, USA). The intercellular $\mathrm{Ca}^{2+}$ levels were measured in the FL1 channel using a flow cytometer.

\section{Immunoprecipitation}

The immunoprecipitation was conducted as previously described $^{50}$. In brief, primary hepatocytes were incubated with LPS $(0.5 \mu \mathrm{g} / \mathrm{mL})$ for $12 \mathrm{~h}$. Then, cells were collected and lysed in a buffer containing $20 \mathrm{mM}$ PIPES, $\mathrm{pH} 6.8,1 \%$ Triton X-100, $150 \mathrm{mM} \mathrm{NaCl}, 150 \mathrm{mM}$ sucrose, $0.2 \%$ sodium deoxycholate, $500 \mu \mathrm{M}$ EDTA, and protease inhibitors using a mortar for $5 \mathrm{~min}$ on ice. After centrifugation, supernatants were diluted to $2 \mu \mathrm{g} / \mathrm{mL}$ in dilution buffer containing $20 \mathrm{mM}$ PIPES, pH 6.8, $1 \%$ Triton X-100, $150 \mathrm{mM} \mathrm{NaCl}, 150 \mathrm{mM}$ sucrose, $2.5 \mathrm{mM} \mathrm{MgCl}$, and 2.5 $\mathrm{mM} \mathrm{MnCl}_{2}$. Primary antibody-conjugated protein A beads were incubated with the lysates for $2 \mathrm{~h}$ at $4{ }^{\circ} \mathrm{C}$ before washing with dilution buffer. The subsequent immunoblot analysis was conducted using the abovementioned methods. The chemicals were purchased from Sigma.

\section{Luciferase reporter assay}

The predicted 3'-UTR sequence (295 bp) of HIPK2 was cloned from the genomic DNA of primary hepatocytes, 

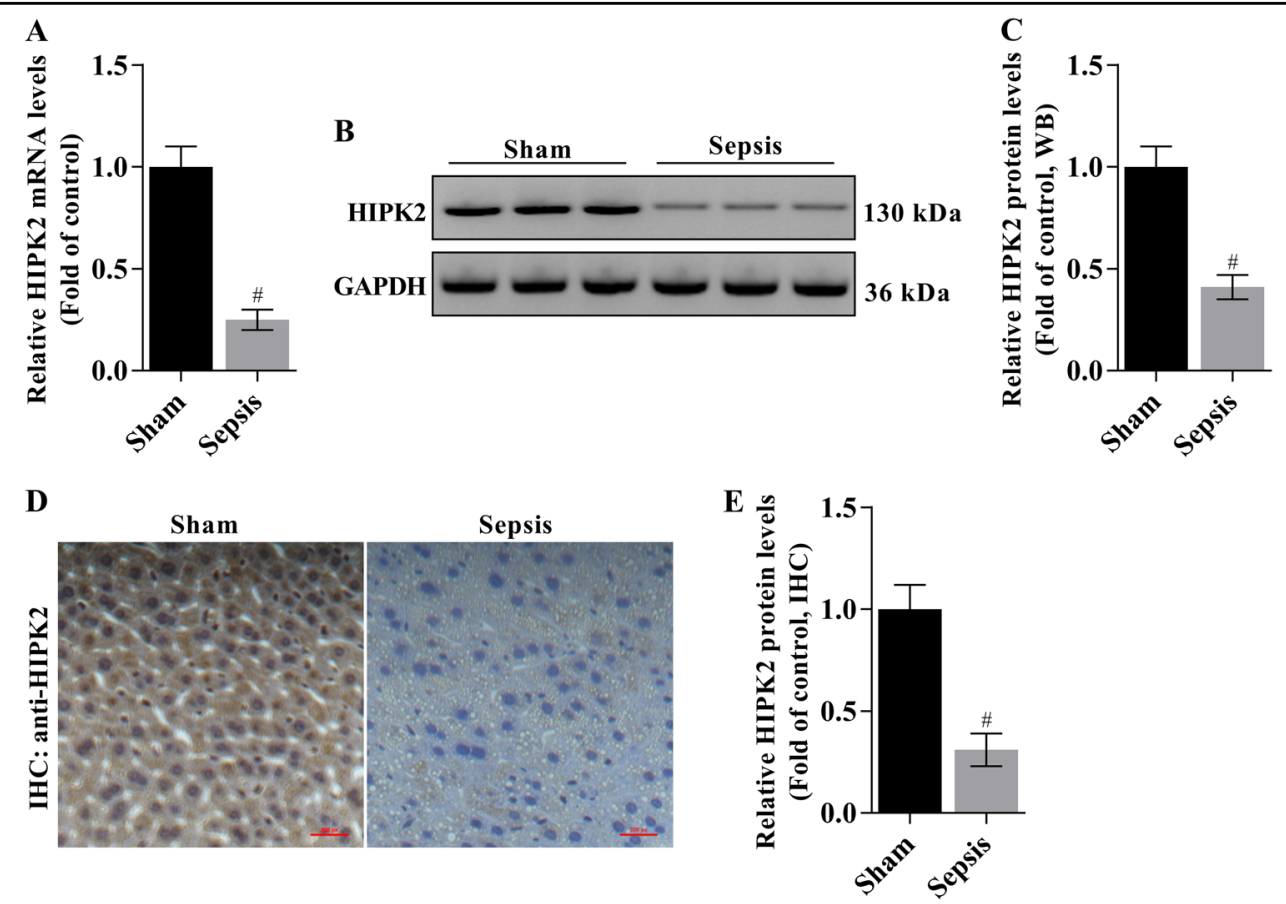

Fig. 1 HIPK2 is expressed at lower levels in liver tissues from mice with CLP-induced liver injury. a Analysis of levels of the HIPK2 mRNA by Q-PCR; GAPDH was used as an internal control. The data are presented as means \pm SEM $(n=3), \# p<0.05$ compared with the sham group. $\mathbf{b}$, $\mathbf{c}$ Western blot analysis of levels of the HIPK2 protein (b) and the results of the corresponding semi-quantitative analysis of levels of the HIPK2 protein based on the optical density measured using ImageJ software (c); the data are presented as means \pm SEM and are representative of three separate experiments, \#p < 0.05 compared with the sham group. $\mathbf{d}$, e Images of IHC staining for the HIPK2 protein (d) and the results of the corresponding semi-quantitative analysis of levels of the HIPK2 protein based on the optical density measured using ImageJ software (e). The data are presented as means $\pm \operatorname{SEM}(n=3), \# p<0.05$ compared with the sham group. The liver and serum samples were obtained from mice $16 \mathrm{~h}$ after the CLP surgery

and then the sequence was inserted into the pmir-GLO empty luciferase reporter vector (Promega, WI, USA). The predicted promoter sequence ( $-300 \mathrm{bp}$ to $+10 \mathrm{bp})$ of HIPK2 was inserted into the pGL-3 basic luciferase reporter vector from Promega. For further studies, primary hepatocytes were co-transfected with the internal control vector pmir-GLO (Promega) and pmir-GLO-HIPK2 3'UTR using the Lipofectamine 2000 reagent (Thermo Fisher Scientific) for $20 \mathrm{~h}$, followed by an incubation with the indicated chemicals for $10 \mathrm{~h}$. Similarly, hepatocytes were co-transfected with the empty vector pGL-3 basic (Promega) and the pGL-3 vector containing the HIPK2 promoter using the Lipofectamine 2000 reagent for $20 \mathrm{~h}$; the $\mathrm{pRL}$ vector was used as an internal control. Cells were then incubated with the indicated chemicals for $10 \mathrm{~h}$. The luciferase reporter activities were determined using the Dual-Glo luciferase assay system from Promega. The drugs and concentrations used in the present study were as follows: $5 \mu \mathrm{M}$ resveratrol, $30 \mu \mathrm{M}$ aspirin, $10 \mu \mathrm{M}$ vitamin $\mathrm{E}$, and $15 \mu \mathrm{M}$ ursolic acid. The compounds were purchased from MedChemExpress NJ, USA).

\section{Statistical analysis}

All data are presented as means \pm standard deviations. Data were analysed using Student' $s t$ tests (comparisons between two groups) or a one-way analysis of variance test (comparisons between multiple group) followed by a post hoc analysis using Tukey's honestly significant difference test with SPSS 17.0 software (SPSS, Inc., Chicago, IL, USA). Differences were considered statistically significant with a $p$ value $<0.05$.

\section{Results}

Expression of HIPK2 in the livers of CLP-induced mice

We analysed hepatic HIPK2 expression to initially examine the alterations in HIPK2 expression during sepsis. Lower levels of the HIPK2 mRNA were observed in the livers of CLP-induced mice, as analysed by Q-PCR (Fig. 1a). Similarly, a lower level of the HIPK2 protein was detected in liver tissues from CLP-induced mice than in the control group (sham), as determined by western blotting and IHC (Fig. 1b-e).

\section{HIPK2 overexpression increases the survival rate and improves CLP-induced liver injury in mice}

Next, we overexpressed HIPK2 to investigate possible hepatic alterations. The Ad-HIPK2 and Ad-shHIPK2 adenoviruses successfully altered HIPK2 expression in the liver but not in other organs (Fig. 2a, b). Based on this premise, the 16-day survival rate was $16.7 \%$ 


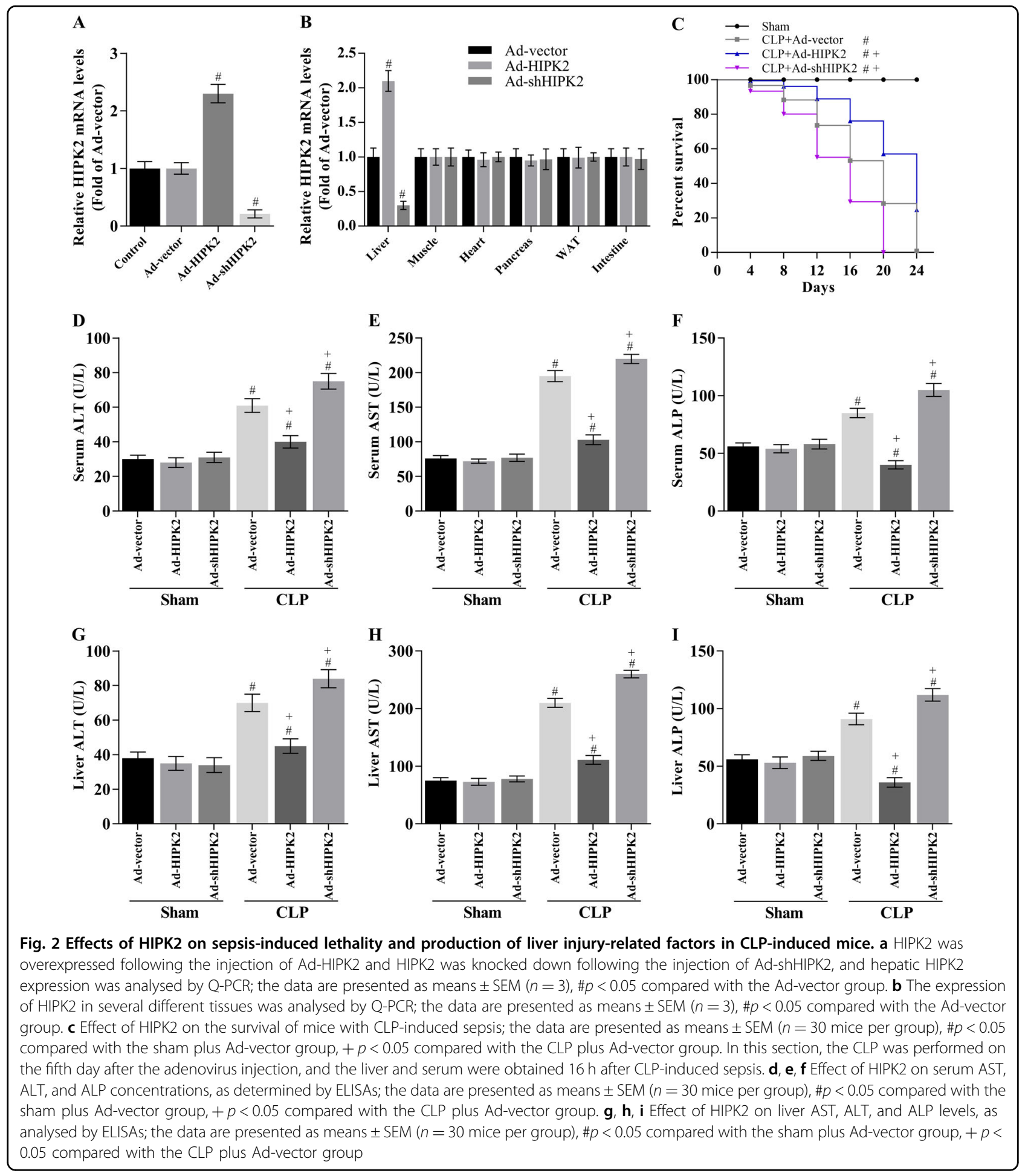

(5 of 30 mice) in the CLP-induced sepsis group, $60.0 \%$ (18 of 30 mice) in the Ad-HIPK2-injected sepsis group, $6.67 \%$ (2 of 30 mice) in the Ad-shHIPK2injected sepsis group (Fig. 2c) and 100\% in the control group (30 mice). Compared with that in the sepsis group, the 16-day survival rate of the Ad-HIPK2- treated sepsis group was improved $(p<0.05)$ (Fig. 2c), indicating that the pretreatment of mice with AdHIPK2 before CLP significantly decreased lethality compared to that in animals with CLP-induced sepsis. However, knockdown of HIPK2 by Ad-shHIPK2 may increase lethality. 
Serum and liver levels of the liver-specific enzymes AST, ALT, and ALP were determined to further analyse the extent of CLP-induced liver dysfunction. Higher AST, ALT, and ALP levels were observed in septic mice than in the sham (normal) group, and Ad-HIPK2 significantly decreased AST, ALT, and ALP levels in the serum and liver of septic mice (Fig. 2d-i). In contrast, knockdown of HIPK2 (Ad-shHIPK2) increased the AST, ALT, and ALP levels in the serum and liver of septic mice (Fig. 2d-i). Combined with the survival rate in Fig. 2c, the data suggest that HIPK2 exerts a protective role in sepsis and sepsis-related acute liver injury that might be related to its ability to decrease the hepatic ALT, AST, and ALP contents.

HIPK2 overexpression reduces the CLP-induced release of inflammatory cytokines into the serum and the levels of oxidative stress-associated indicators in CLP-induced mice

We measured the serum concentrations of TNF- $\alpha$, IL- 6 , and IL-1 $\beta$; analysed the levels of antioxidants such as SOD, GSH, and CAT; and detected the levels of $\mathrm{H}_{2} \mathrm{O}_{2}$, $\mathrm{O}^{-}{ }_{2}$, and $\mathrm{NO}$ in the liver to determine the effects of HIPK2 on inflammation and oxidative stress in the livers of LPS-induced mice. Serum TNF- $\alpha$, IL-6, and IL-1 $\beta$ levels in the CLP group were $40.6 \pm 3.1 \mathrm{ng} / \mathrm{L}, 38.5 \pm 2.8$ $\mathrm{ng} / \mathrm{L}$ and $7.7 \pm 1.9 \mathrm{ng} / \mathrm{L}$, respectively (Fig. $3 \mathrm{a}-\mathrm{c}$ ). HIPK2 overexpression significantly decreased serum TNF- $\alpha$ $(19.2 \pm 2.4 \mathrm{ng} / \mathrm{L})$, IL-6 $(18.7 \pm 2.1 \mathrm{ng} / \mathrm{L})$, and IL- $1 \beta(3.4 \pm$ $1.2 \mathrm{ng} / \mathrm{L}$ ) levels by $\sim 52.7 \%, 51.4 \%$, and $72.6 \%$, respectively. However, HIPK2 knockdown decreased the serum concentrations of TNF- $\alpha(54.5 \pm 3.6 \mathrm{ng} / \mathrm{L}), \mathrm{IL}-6(56.1 \pm 4.0$ $\mathrm{ng} / \mathrm{L})$, and IL- $1 \beta(8.3 \pm 1.5 \mathrm{ng} / \mathrm{L})$ by $\sim 25.8 \%, 34.2 \%$, and $7.8 \%$, respectively (Fig. $3 \mathrm{a}-\mathrm{c}$ ).

On the other hand, the activities of SOD, CAT, and GSH were significantly decreased in mice with CLPinduced sepsis. As expected, HIPK2 overexpression evidently restored CAT (Fig. 3d), GSH (Fig. 3e), and SOD activities (Fig. 3f). Furthermore, hepatic $\mathrm{H}_{2} \mathrm{O}_{2}, \mathrm{O}^{-}{ }_{2}$, and $\mathrm{NO}$ levels were analysed in mice. The $\mathrm{H}_{2} \mathrm{O}_{2}, \mathrm{O}^{-}{ }_{2}$, and $\mathrm{NO}$ levels were elevated in the livers of CLP-induced mice, and HIPK2 overexpression significantly inhibited $\mathrm{H}_{2} \mathrm{O}_{2}, \mathrm{O}^{-}{ }_{2}$, and $\mathrm{NO}$ production in the livers of CLP model mice (Fig. 3g-i). In contrast, HIPK2 knockdown obviously decreased the SOD, CAT, and GSH activities and increased the release of $\mathrm{H}_{2} \mathrm{O}_{2}, \mathrm{O}^{-}{ }_{2}$, and $\mathrm{NO}$ (Fig. $3 \mathrm{~d}-\mathrm{i}$ ). Interestingly, the expression of the antioxidant transcription factor NRF2 and its target gene NQO1 increased after HIPK2 was overexpressed in septic mice (Supporting Fig. 1A and 1B), providing a potential explanation for the mechanism by which HIPK2 overexpression reduces oxidative stress. Thus, we reasonably assumed that reductions in ROS production and oxidative stress might be involved in the protective effects of HIPK2 on the liver in CLP-induced mice.
HIPK2 overexpression increases the autophagic flux in the livers of CLP-induced mice and inhibits LPS-induced apoptosis of primary hepatocytes

We analysed the levels of the LC3-II and p62 proteins to investigate the effect of HIPK2 on autophagic flux in the livers of CLP-induced mice. In the livers of CLP-induced mice, the levels of the LC3-II and p62 proteins were significantly increased by $\sim 2.1$ - and 2.5 -fold, respectively, compared with those in the control group on the fourth day after CLP (Fig. 4a, b). HIPK2 overexpression increased LC3-II expression (Fig. 4a, b). Bafilomycin A was used to detect the autophagic flux in mice. Bafilomycin A significantly increased the levels of the LC3-II protein. Furthermore, Ad-HIPK2 may enhance the bafilomycin A-induced accumulation of LC3-II (Fig. 4c). Then, we used chloroquine (an autophagic flux inhibitor) to determine the contribution of autophagy to liver protection. Chloroquine increased LC3-II expression in the CLP model (Fig. 4d). Moreover, chloroquine reversed the HIPK2-mediated decrease in mortality and liver injury in CLP mice and increased ALT, AST, and ALP activities in CLP mice compared with those observed following the administration of Ad-HIPK2 alone (Fig. 4e-h).

We also investigated the effect of HIPK2 on the apoptosis of primary hepatocytes. HIPK2 overexpression significantly attenuated the LPS-induced apoptosis of primary hepatocytes (Fig. 4i, j).

\section{HIPK2 overexpression restores the formation of} autophagosomes and autolysosomes in CLP-induced mice

The mature autophagosome is formed by the Atg12-516 L1 complex, Beclin-1, complex and LC3-II. In the present study, the level of the Atg12-5 protein was increased by 1.5 -fold in CLP-induced mice compared with that in the control mice, and this increase was enhanced by HIPK2 overexpression (Fig. 5a, b). However, Beclin-1 expression was not changed by sepsis or HIPK2 overexpression (Fig. 5a, b). Moreover, we analysed the levels of markers of LC3 lipidation, including Atg3 and Atg7. Atg3 expression was reduced by $76.4 \%$ compared with that in the control group, and this reduction was reversed by HIPK2 overexpression (Fig. 5c, d). Furthermore, Atg7 expression was not changed by CLP-induced sepsis, while the levels of this protein were increased upon HIPK2 overexpression (Fig. 5c, d).

Autophagosomes always fuse with lysosomes, resulting in autolysosome formation, which is required for cargo degradation. This process requires LAMP-2 and Rab7 $7^{51-54}$. Thus, we determined the levels of LAMP-2, Rab7, and cathepsin B in the mouse liver. Levels of the LAMP-2 and Rab7 proteins were significantly reduced by $73.1 \%$ and $76.4 \%$, respectively, compared with those in the control group, and this reduction was reversed by the overexpression of HIPK2 (Fig. 6a, b). However, cathepsin 

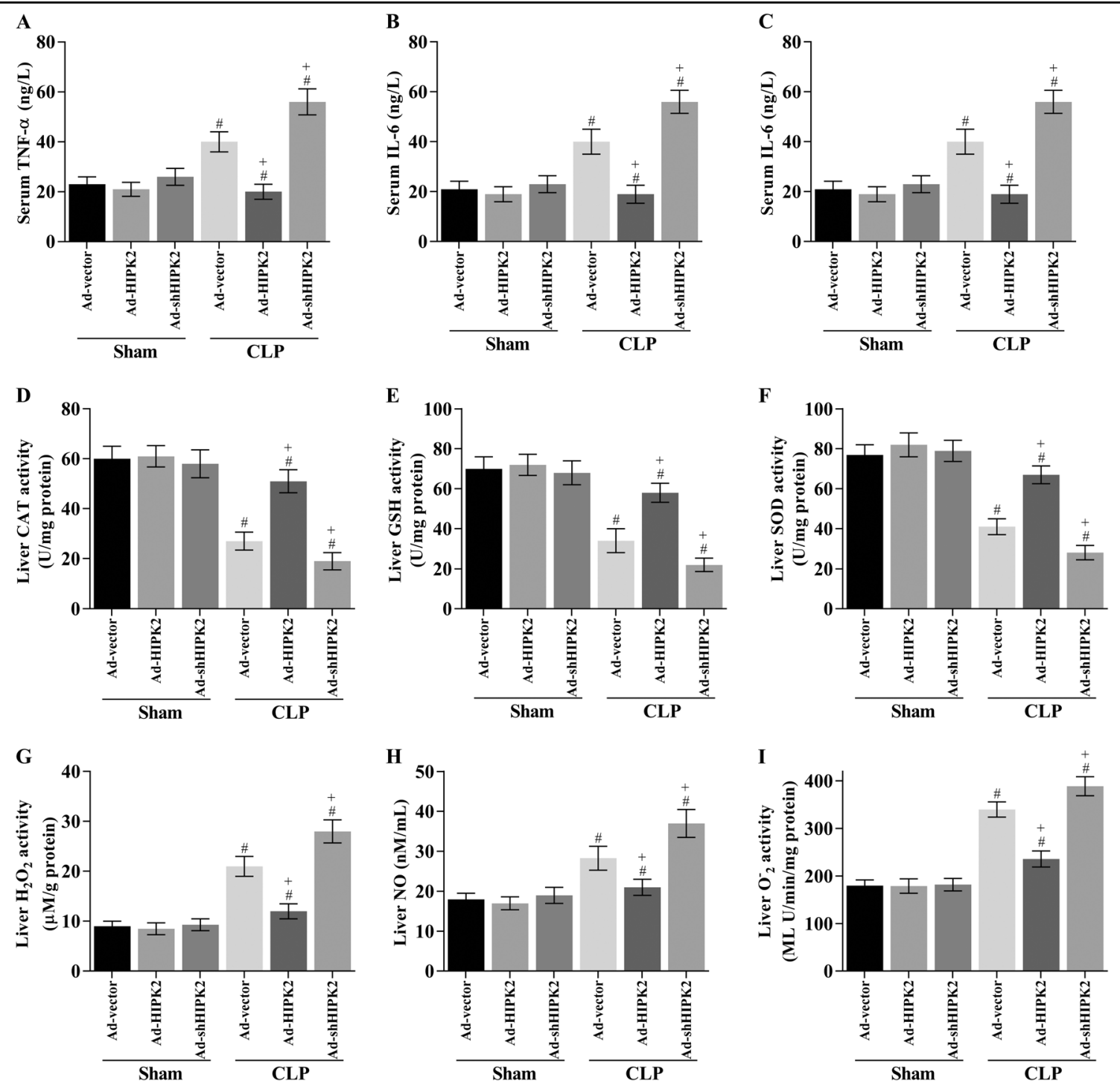

Fig. 3 Effects of HIPK2 on the levels of inflammatory cytokines and oxidative stress-related markers in CLP-induced mice. The CLP surgery was performed on the fifth day after the adenovirus injection and the liver and serum were obtained $16 \mathrm{~h}$ after CLP-induced sepsis. a, b, c Serum TNF-a, IL-1 $\beta$ and IL-6 concentrations were determined using ELISAs; data are presented as means \pm SEM ( $n=30$ mice per group), $\# p<0.05$ compared with the sham plus Ad-vector group, $+p<0.05$ compared with the CLP plus Ad-vector group. $\mathbf{d}$-i Liver CAT (d), GSH (e), SOD (f), $\mathrm{H}_{2} \mathrm{O}_{2}(\mathbf{g}), \mathrm{NO}$ (h), and $\mathrm{O}^{-}{ }_{2}$ (i) concentrations were measured using ELISAs; data are presented as means \pm SEM ( $n=30$ mice per group), \#p $<0.05$ compared with the sham plus Ad-vector group, $+p<0.05$ compared with the CLP plus Ad-vector group

B expression was not altered in any group. To prove that overexpression of HIPK2 may significantly restore sepsisinduced dysregulation of autophagosome-lysosome fusion, the LC3-II and LAMP-2 protein expression levels in the mouse livers were also analysed by immunohistochemistry. Compared with that in the control group, the LC3-II staining was significantly increased and LAMP-2 staining was decreased by CLP (Fig. 6c, d). Interestingly, HIPK2 overexpression enhanced the increase in LC3 expression and reversed the decrease in levels of the LAMP-2 protein (Fig. 6c, d). As evidenced by $\mathrm{H}$ \& $\mathrm{E}$ staining, HIPK2 overexpression exerted a beneficial effect on preserving the hepatocyte shapes in mice with CLPinduced liver injury (Fig. 6e).

\section{Effect of HIPK2 on CLP-induced mTOR and calpain signalling}

The calpain system and mTOR signalling play important roles in CLP-induced liver injury ${ }^{21-25}$. We analysed mTOR-mediated signalling and the mTOR-independent pathway (calpain system) to explore the mechanisms by which HIPK2 activates autophagy in response to CLPinduced liver injury. CLP mice exhibited higher levels of phosphorylated mTOR and its downstream targets, 4E- 


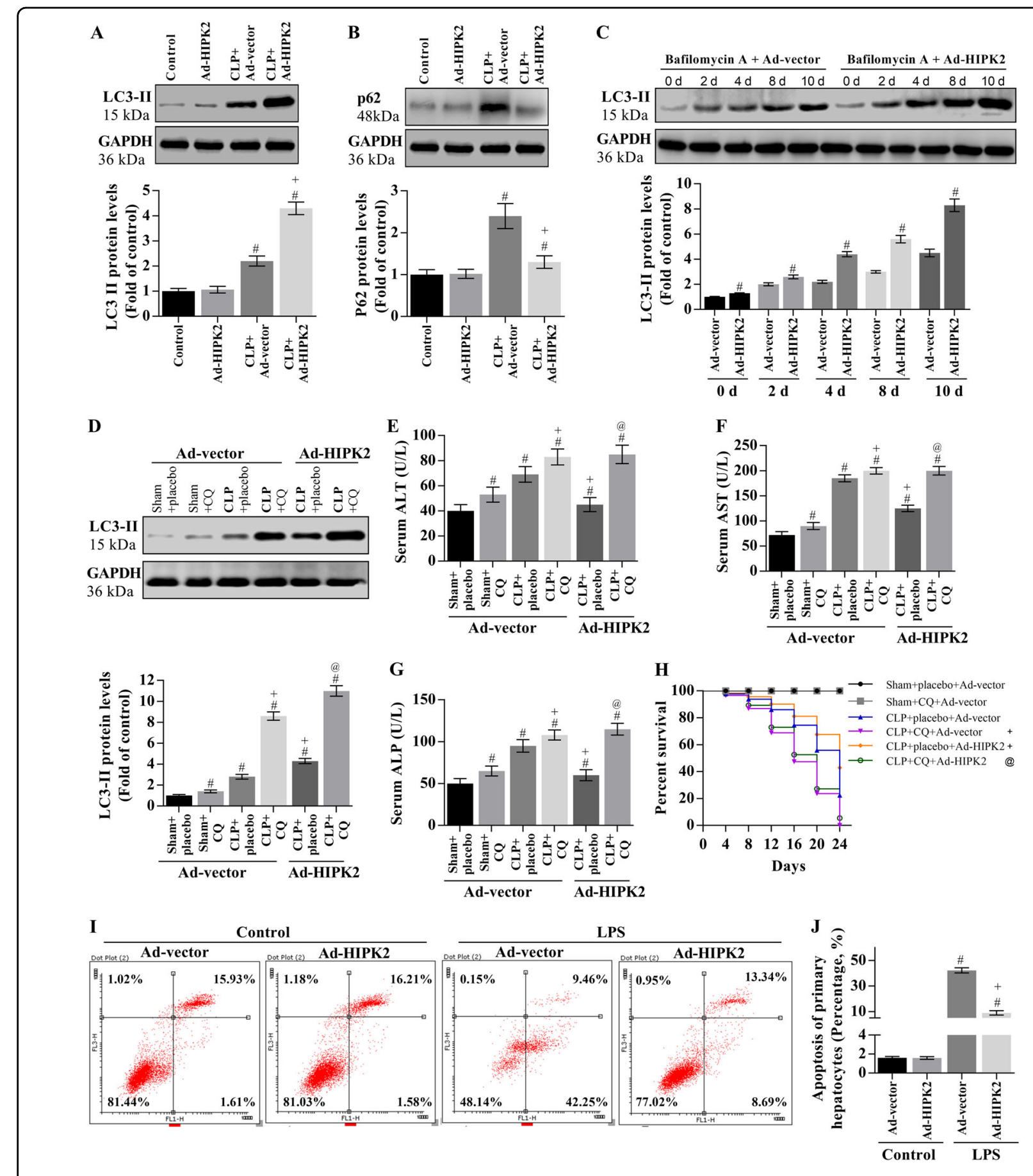

Fig. 4 (See legend on next page.)

BP1 and p70S6K, than the control group (Fig. 7a, b). The CLP-induced increase in levels of the calpain 1 protein was significantly attenuated by HIPK2 overexpression (Fig. 7a, c). However, no changes in levels of the calpain 2 protein were observed in any group (Fig. 7a, c). Furthermore, CLP mice showed increased levels of the cleaved Atg5 protein $(24 \mathrm{kD})$, which is a downstream target of calpain $1^{55}$, compared with those in the control group (Fig. 7a,c). However, HIPK2 overexpression attenuated the increase in cleaved Atg5 levels in the livers of CLPinduced mice (Fig. 7a, c).

To investigate the role of mTOR signalling in HIPK2induced autophagy, we inhibited the activity of mTOR by using rapamycin. HIPK2 knockdown did not change the 
(see figure on previous page)

Fig. 4 HIPK2 overexpression increases the autophagic flux in mice with CLP-induced liver injury and inhibits the LPS-induced apoptosis of primary hepatocytes. $\mathbf{a}$, b Effects of HIPK2 on levels of the LC3-II and p62 proteins in the liver; the data are presented as means \pm SEM and are representative of three separate experiments, $\# p<0.05$ compared with the control group and $+p<0.05$ compared with the CLP plus Ad-vector group. $\mathbf{c}$ Effects of Ad-HIPK2 on hepatic LC3-II expression in of the group treated with bafilomycin A $(0.2 \mu \mathrm{M})$; the data are presented as means \pm SEM and are representative of three separate experiments, $\# p<0.05$ compared with the Ad-vector (control) group at the indicated time point. $\mathbf{d}$ Effect of chloroquine (CQ, $50 \mathrm{mg} / \mathrm{kg}$ per day) on levels of the LC3-II protein in the liver; the data are presented as means \pm SEM and are representative of three separate experiments, $\# p<0.05$ compared with the sham plus Ad-vector group in the absence of $C Q,+p<0.05$ compared with the CLP plus Advector group in the absence of CQ, and @p $<0.05$ compared with the CLP plus Ad-HIPK2 group in the absence of CQ. e, $\mathbf{f}, \mathbf{g}$ Effect of chloroquine (CQ) on serum concentrations of AST, ALT, and ALP in the HIPK2-overexpressing liver tissues, as determined by ELISAs; the data are presented as means \pm SEM ( $n=30$ mice per group), \#p $<0.05$ compared with the sham plus Ad-vector group in the absence of $C Q,+p<0.05$ compared with the CLP plus Ad-vector group in the absence of CQ, and @p $<0.05$ compared with the CLP plus Ad-HIPK2 group in the absence of CQ. $\mathbf{h}$ Effect of chloroquine (CQ) on the sepsis-induced lethality of HIPK2-overexpressing mice ( $n=30$ mice per group); $+p<0.05$ compared with the CLP plus Advector group in the absence of CQ and @p $<0.05$ compared with the CLP plus Ad-HIPK2 group in the absence of CQ. In this section, CLP ( $n=30$ ) was performed on the fifth day after the adenovirus injection, and CQ $(50 \mathrm{mg} / \mathrm{kg})$ was administered $1 \mathrm{~h}$ prior to CLP. $\mathbf{i}$ Effect of HIPK2 overexpression on LPS $(0.5 \mathrm{\mu g} / \mathrm{mL})$-induced apoptosis of primary hepatocytes, as analysed by flow cytometry. $\mathbf{j}$ Percentage of apoptotic cells induced by LPS; data are presented as means \pm SEM and are representative of three separate experiments, $\# p<0.05$ compared with the Ad-vector group, $+p<0.05$ compared with the LPS plus Ad-vector group

A

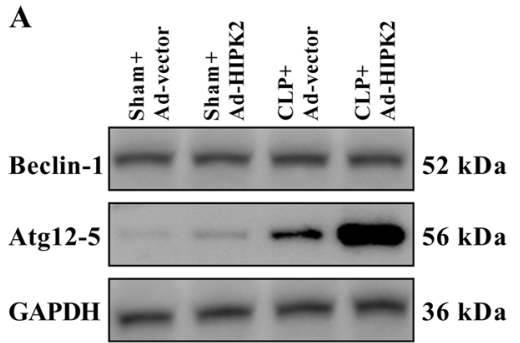

B

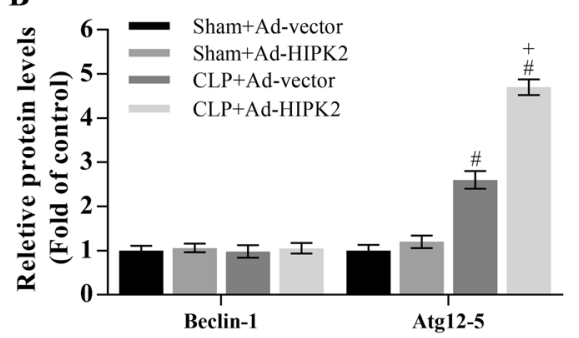

C

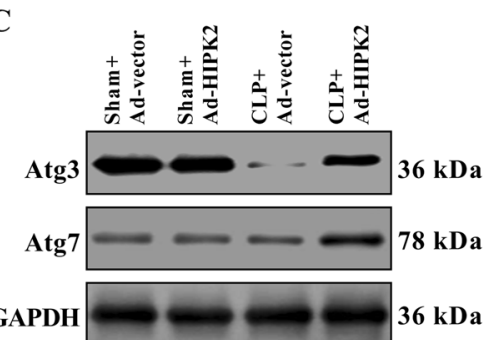

D

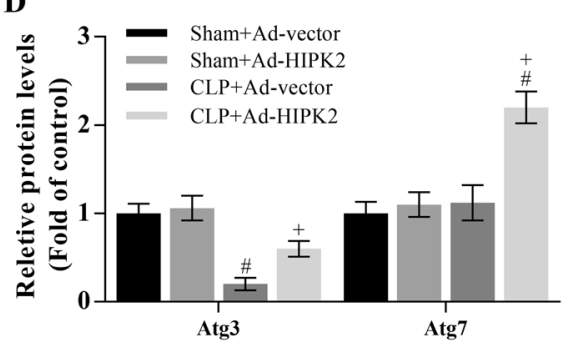

Fig. 5 HIPK2 overexpression restores autophagosome formation in CLP-induced mice. a Effect of HIPK2 overexpression on Beclin-1 and Atg125 levels, as analysed by western blotting; $C L P(n=30)$ was performed on the fourth day after the adenovirus injection. Data are presented as means \pm SEM and are representative of three separate experiments; $\# p<0.05$ compared with the sham plus Ad-vector group (control), $+p<0.05$ compared with the CLP plus Ad-vector group. b Effect of HIPK2 overexpression on Atg3 and Atg7 levels, as analysed by western blotting. Data are presented as means \pm SEM and are representative of three separate experiments, $\# p<0.05$ compared with the sham plus Ad-vector group, $+p<0.05$ compared with the CLP plus Ad-vector group

activation of the mTOR pathway (Fig. 7d, e). However, HIPK2 knockdown significantly increased the levels of calpain 1 and cleaved Atg5 (Fig. 7d, f).

\section{HIPK2 overexpression reduces elevated cytosolic $\mathrm{Ca}^{2+}$ concentrations in LPS-treated primary hepatocytes by interacting with calpain 1 and calmodulin}

Calpain is a $\mathrm{Ca}^{2+}$-dependent cysteine protease, and calmodulin activity may be regulated by $\mathrm{Ca}^{2+}$ to play an important role in cellular signal transduction. Thus, we investigated the interactions of HIPK2 with calpain 1 and calmodulin in LPS-induced hepatocytes. HIPK2 interacted with calpain 1 and calmodulin in hepatocytes (Fig. 8a). However, the interaction of HIPK2 with calpain 1 was weaker in LPS-induced hepatocytes than in the control group and, in contrast, the interaction of HIPK2 and calmodulin was enhanced in LPS-induced hepatocytes compared with that in the control group (Fig. 8a). HIPK2 overexpression significantly decreased the LPSinduced elevation in $\mathrm{Ca}^{2+}$ concentrations, as evidenced by flow cytometry (Fig. 8b). Moreover, several antiinflammatory drugs significantly increased the levels of the HIPK2 protein and mRNA by activating the promoter of the HIPK 2 gene and by maintaining the stability of the 


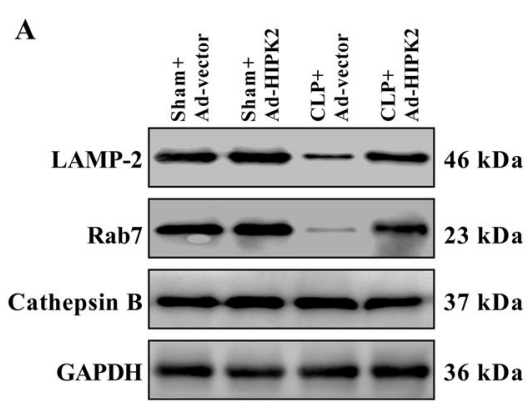

B
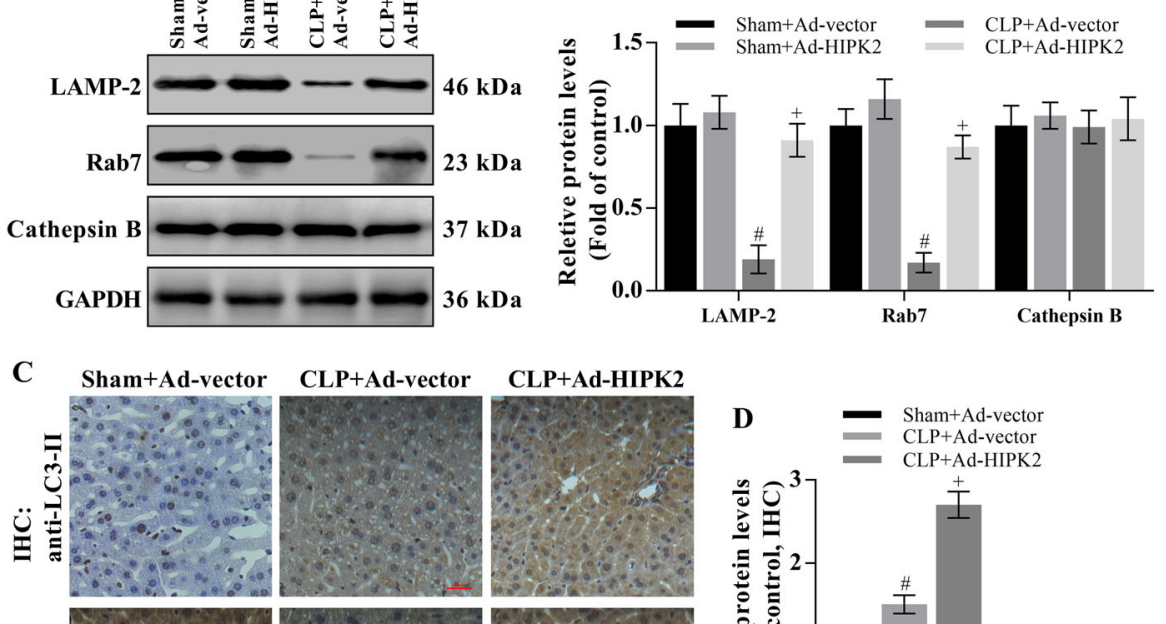

CLP+Ad-vector

CLP+Ad-HIPK2
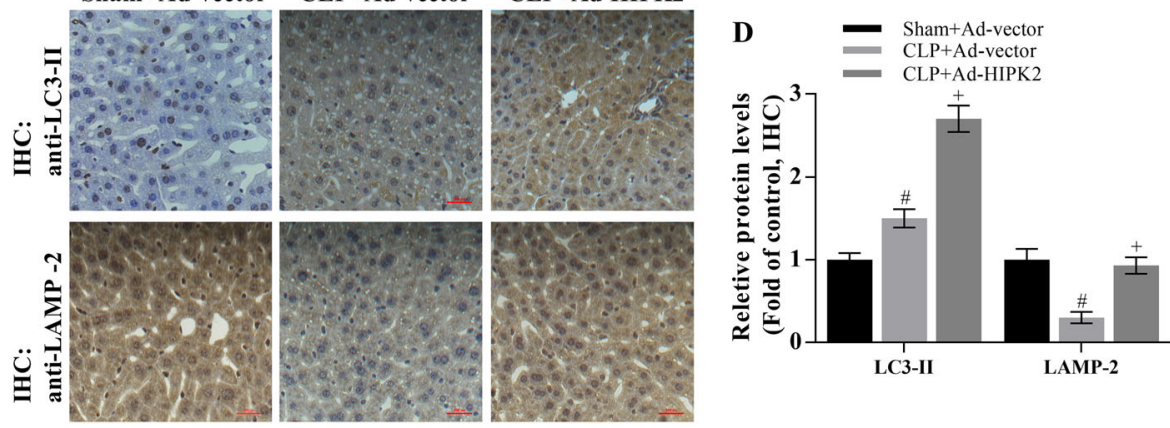

E

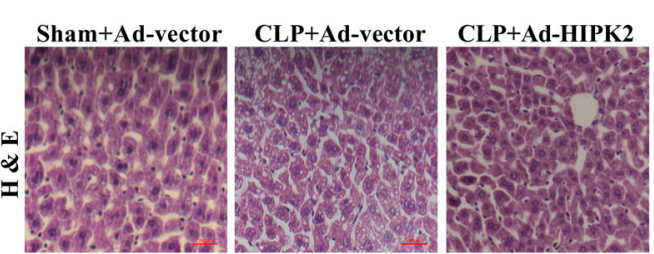

Fig. 6 HIPK2 overexpression restores autophagosome-lysosome fusion and degradation in CLP-induced mice. $\mathbf{a}$, $\mathbf{b}$ Effects of Ad-HIPK2 on levels of the LAMP-2, Rab7, and cathepsin B proteins in the liver, as analysed by western blotting (a) and the results of the corresponding semiquantitative analysis of levels of the HIPK2 protein based on the optical density measured using ImageJ software (b); data are presented as means \pm SEM and are representative of three separate experiments, $\# p<0.05$ compared with the sham plus Ad-vector group (control), $+p<0.05$ compared with the CLP plus Ad-vector group. $\mathbf{c}$, $\mathbf{d}$ Effects of Ad-HIPK2 on levels of the LC3 and LAMP-2 proteins in the liver, as determined by IHC (c) and the results of the corresponding semi-quantitative analysis of levels of the HIPK2 protein based on the optical density measured using ImageJ software (d); and data are presented as means \pm SEM and are representative of six microscopic fields per group, $\# p<0.05$ compared with the sham plus Advector group (control), $+p<0.05$ compared with the CLP plus Ad-vector group. e Images of H \& E-stained liver sections captured at a magnification of $200 \times$ (six microscopic fields per group)

3'-UTR, confirming that HIPK2 is a target for sepsis treatments (Fig. 8c-f). Finally, the indicated drugs failed to upregulate LC3-II expression, and they also failed to downregulate calpain 1 expression after HIPK2 knockdown (Fig. 8g).

\section{Discussion}

Autophagy plays an important role in attenuating the sepsis-induced dysfunction of multiple organs and might be an attractive target for the future management of sepsis $^{16}$. Inhibition of autophagy results in increased mortality by causing organ dysfunction and depleting immune cells in patients with sepsis ${ }^{17,18}$. In contrast, upregulation of autophagy inhibits hepatocyte apoptosis and ameliorates liver injury ${ }^{56,57}$. HIPK2 plays a dual role in cancers by either functioning as a tumour suppressor or facilitating tumour progression ${ }^{27-33}$, suggesting that HIPK2 is a positive effector or a negative effector of apoptosis. Moreover, HIPK2 functionally interacts with $\mathrm{NRF}^{34}$, a transcription factor involved in protecting the liver and autophagy ${ }^{35-40}$. Thus, HIPK2 might play an important role in protecting the liver. However, the precise mechanisms by which HIPK2 regulates autophagy and sepsis remain unclear. In this study, HIPK2 overexpression increased the autophagic flux and subsequently increased the survival rate in CLP-induced mice.

Previous studies have demonstrated that autophagy is stimulated in various organs as an early step of sepsis and is characterized by enhanced autophagic vacuole accumulation and the expression of autophagy-associated markers, such as LC3-II, in the livers of CLP-induced animals $^{56,58}$. Activated autophagy exerts a series of 

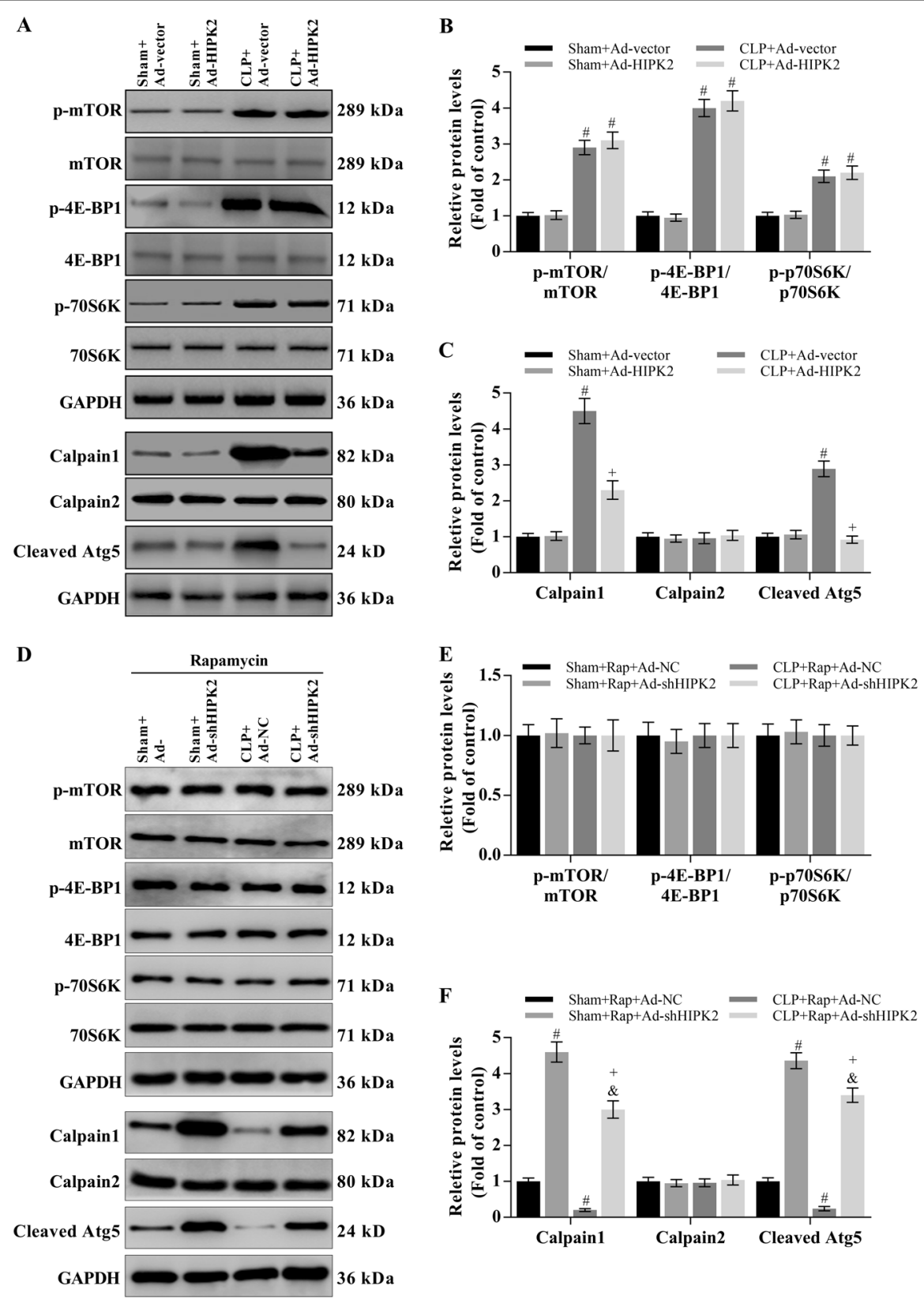

Fig. 7 Effect of HIPK2 on CLP-induced mTOR and calpain activation in the mouse liver. $\mathbf{a}, \mathbf{b}$, c Effect of Ad-HIPK2 on p-mTOR, p-4E-BP1, and pp70S6K levels, as determined by western blotting $(\mathbf{a}, \mathbf{b})$ and effect of Ad-HIPK2 on the activation of the calpain system, as analysed by western blotting $(\mathbf{a}, \mathbf{c})$. The results of the corresponding semi-quantitative analysis of protein levels was based on the optical density measured using ImageJ software. Data are presented as means \pm SEM and are representative of three separate experiments, $\# p<0.05$ compared with the sham plus Advector group (control), $+p<0.05$ compared with the CLP plus Ad-vector group. $\mathbf{d}$, e, $\mathbf{f}$ Effect of Ad-shHIPK2 on p-mTOR, p-4E-BP1 and p-p7OS6K levels after the administration of rapamycin ( $1 \mathrm{mg} / \mathrm{kg}$ per day) for $24 \mathrm{~h}$, as determined by western blotting (d, e) and effect of Ad-shHIPK2 on the activation of the calpain system in the presence of rapamycin, as analysed by western blotting ( $\mathbf{d}$, $\mathbf{f}$ ). Results of the corresponding semi-quantitative analysis of protein levels based on the optical density measured using ImageJ software. Data are presented as means \pm SEM and are representative of three separate experiments, $\# p<0.05$ compared with the sham plus Ad-NC group, $+p<0.05$ compared with the CLP plus Ad-NC group, \& $p<0.05$ compared with the sham plus Ad-shHIPK2 group

beneficial effects by eliminating invading pathogens, inhibiting overproduction of stress-related proteins and improving the function of multiple organelles ${ }^{59}$. LC3-II is only expressed on the mature autophagosomes ${ }^{56}$.
SQSTM1/p62, a ubiquitin binding protein, is a robust marker of dynamic autophagic flux, and p62 always directly interacts with LC3-II ${ }^{56}$. Both the LC3-II and p62 proteins are degraded with their cargos in the 


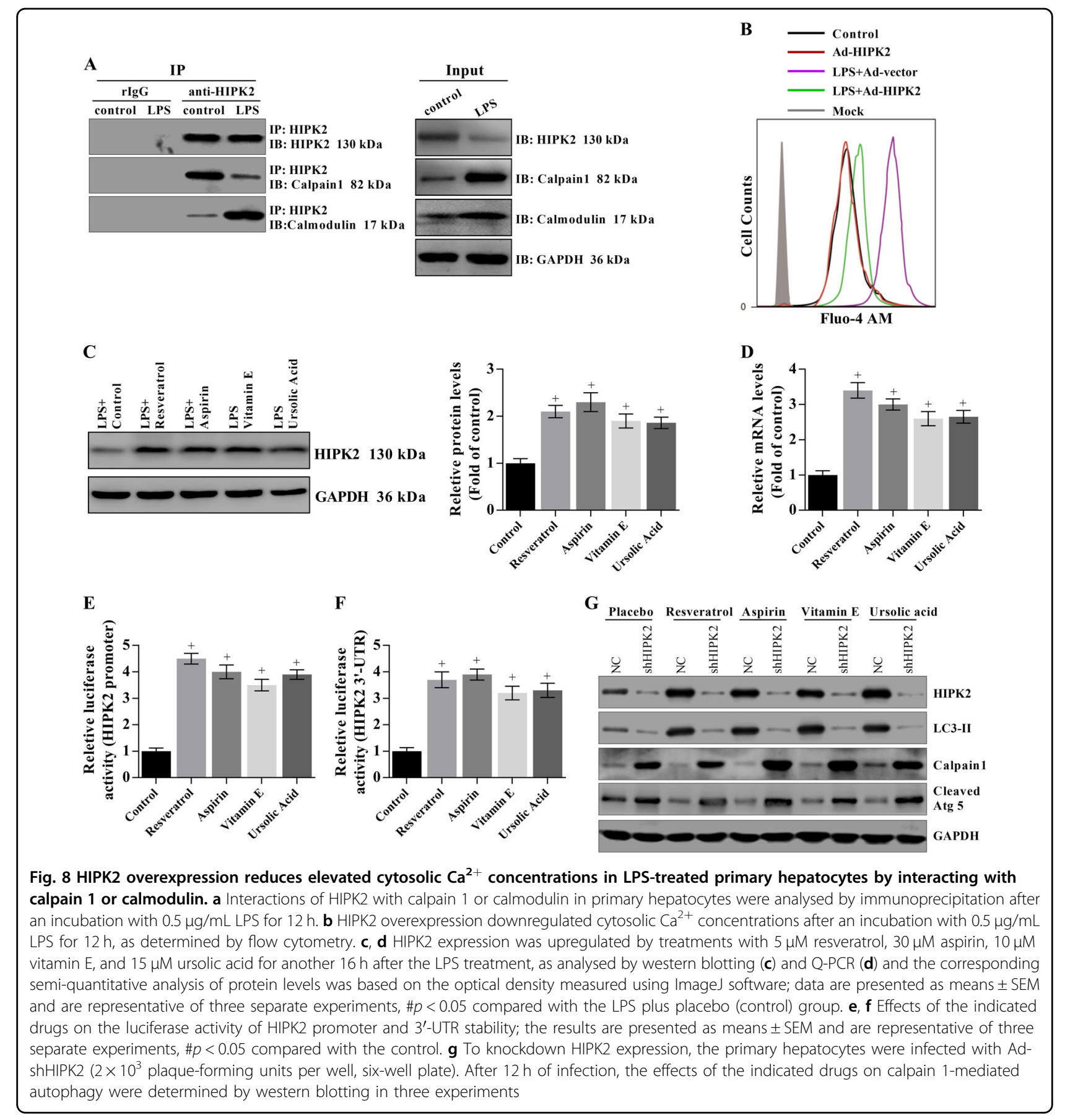

autolysosome. In the present study, sepsis-induced liver injury was associated with autophagic flux. The hepatic levels of the LC3-II and p62 proteins were significantly increased after CLP. Chloroquine, an autophagy inhibitor, significantly enhanced the increased levels of the LC3-II and p62 proteins. Moreover, chloroquine may enhance liver injury, as evidenced by a lower survival rate. Based on these data, suppression of autophagic flux may be responsible for liver injury in patients with sepsis. Moreover, HIPK2 significantly attenuated liver injury by upregulating LC3-II expression, decreasing levels of the p62 protein, and improving sepsis-induced liver injury that was manifested by decreased levels of ALT, AST, ALP, and inflammatory factors in the liver and serum of CLP mice, leading to the increased survival of CLP mice. Importantly, the HIPK2-mediated restoration of autophagic flux was blocked by chloroquine, and the protective effect of HIPK2 on liver injury was also blocked by chloroquine treatment. Thus, HIPK2 overexpression ameliorated liver injury by restoring the autophagic flux in 
the livers of mice with sepsis. In addition, NRF2 and NQO1 expression were increased after the overexpression of HIPK2 in septic mice.

The autophagy process involves several steps: initiation and nucleation, expansion, autophagosome formation, autophagosome-lysosome fusion and degradation ${ }^{60}$. Initially, the isolation of membranes from the endomembrane system, such as the Golgi apparatus and endoplasmic reticulum, is initiated by the Beclin-1/Vps34 complex, which is regulated by the ULK complex ${ }^{17,61-63}$. Following nucleation, Atg12-Atg5-conjugated and membrane-associated LC3-II may play important roles in the autophagosome formation ${ }^{17,61-63}$. The Atg12-Atg5 complex always binds to the outer membrane of the phagophore and separates after mature autophagosome formation, which is ultimately completed by the LC3-II protein ${ }^{17,61-63}$. In this process, the Atg3, Atg4, and Atg7 enzymes promote LC3-II production, and autophagosome formation is impaired when Atg3, Atg5, and Atg7 are silenced, according to several studies ${ }^{17,61-63}$. In the present study, HIPK2 overexpression significantly enhanced the increased expression of the Atg12-5 complex and restored the reduced Atg3 expression in mice with sepsisinduced liver injury. HIPK2 overexpression increased the level of the Atg7 protein, which was not affected by CLPinduced sepsis, suggesting that HIPK2 overexpression promotes phagophore expansion and increases mature autophagosome formation in sepsis. In addition, neither HIPK2 overexpression nor sepsis altered the level of the Beclin-1 protein. Thus, HIPK2-mediated autophagy is likely independent of Beclin-1 in sepsis.

The fusion of mature autophagosomes with lysosomes is a key event in the degradation of autophagic cargos ${ }^{64}$. LAMP-1 and LAMP-2 are required for the fusion process $^{64,65}$. When LAMP-2 and Rab7 are downregulated, fusion is impaired and autophagosomes accumulate ${ }^{51-54}$. In the present study, levels of the LAMP-2 and Rab7 proteins were significantly decreased in mice with sepsisinduced liver injury, but levels of the cathepsin B protein were not changed. HIPK2 overexpression ameliorated the decrease in LAMP-2 and Rab7 expression. Furthermore, staining for the LC3-II protein was significantly increased upon overexpression of HIPK2, and LAMP-2 expression was restored by overexpression of HIPK2 in the livers of mice with sepsis. Consequently, HIPK2 overexpression may restore autophagosome-lysosome fusion in mice with sepsis-induced liver injury.

The functions of mTOR have been studied extensively. Under normal conditions, the kinase activity of mTOR is inhibited through a direct interaction with the Atg1Atg13 complex ${ }^{66,67}$. In the skeletal muscle of mice with sepsis, decreased mTOR activation is associated with reduced protein synthesis ${ }^{67}$. Inhibition of mTOR exerts protective effects on acute kidney injury in mice with endotoxaemia ${ }^{21}$. On the other hand, calpain is a $\mathrm{Ca}^{2+}$ dependent cysteine protease that is involved in various biological events, including signalling pathways, apoptosis and autophagy. The activities of calpain 1 and calpain 2, the two main isoforms of calpain, are regulated by micromolar and millimolar $\mathrm{Ca}^{2+}$ concentrations, respectively. Therefore, a loss of $\mathrm{Ca}^{2+}$ homeostasis affects calpain activity, leading to organ injury ${ }^{22}$. The calpain system suppresses autophagy progression by directly cleaving Atg proteins throughout the autophagy process ${ }^{23,24}$. For example, Atg5 is a specific target of calpains, which often participate in the crosstalk between apoptosis and autophagy ${ }^{68}$. Importantly, the activities and levels of calpain proteins are increased in CLP-induced sepsis models, indicating that calpains inhibit autophagy in sepsis ${ }^{25}$. In the present study, the levels of calpain 1 and cleaved Atg5 and the phosphorylation/activity of mTOR were significantly increased in the livers of mice with sepsis. HIPK2 overexpression reduced the sepsis-mediated increase in calpain 1 and cleaved Atg5 levels but did not affect mTOR levels. Moreover, HIPK2 knockdown significantly increased calpain 1 levels. However, HIPK2 knockdown did not change mTOR signalling when mTOR activity was suppressed by rapamycin. Based on our results, calpain 1 signalling, but not the mTOR pathway, is involved in the HIPK2-mediated increase in autophagic flux. In addition, HPK-1, the sole orthologue of the mammalian HIPK family in Caenorhabditis elegans, is required for the formation of autophagosomes and induction of autophagy-related gene expression after nutrient deprivation or mTOR inactivation ${ }^{69}$. Another orthologue of the human HIPK2 gene, Yak1 kinase in Saccharomyces cerevisiae, is one such target that is negatively regulated by both the PKA and TOR pathways $^{70,71}$. Thus, HIPK2 and its orthologous proteins (HPK-1 and Yak1) are downstream targets of mTOR.

Moreover, the interaction of HIPK2 with calpain 1 was reduced in mice with sepsis-induced liver injury, and the interaction of HIPK2 with calmodulin was enhanced in septic mice. Calpain 1 activity was monitored by measuring cleaved Atg5 levels ${ }^{55}$. HIPK2 overexpression significantly downregulated the increased $\mathrm{Ca}^{2+}$ concentrations in mice with sepsis-induced liver injury. Based on these data, HIPK2 may inhibit calpain 1 activity under normal conditions by interacting with calpain 1 , and in response to sepsis, HIPK2 dissociates from calpain 1 and then interacts with calmodulin to decrease $\mathrm{Ca}^{2+}$ levels, resulting in attenuation of sepsis-induced liver injury. Resveratrol, aspirin, vitamin E, and ursolic acid have been reported to protect the liver ${ }^{72-74}$. These compounds significantly increased the levels of the HIPK2 mRNA and protein by regulating promoter activity and the stability of the 3'-UTR of the HIPK2 gene, indicating that HIPK2 might be a common and promising target for 
sepsis treatment. Finally, these drugs failed to downregulate calpain 1 expression after HIPK2 knockdown, implying that HIPK2 is indispensably involved in the protective effects of these drugs.

In conclusion, HIPK2 protected the liver from sepsisinduced injury through calpain 1-mediated autophagy. HIPK2 may inhibit calpain 1 activity and expression under normal conditions by interacting with calpain 1 , and in response to sepsis, HIPK2 dissociates from calpain 1 and then interacts with calmodulin to decrease $\mathrm{Ca}^{2+}$ levels.

\section{Acknowledgements}

We appreciate the financial support from the National Natural Science Foundation of China (Nos. 81701062, 81772105, and 81671887), the Shanghai Outstanding Youth Medical Professionals Training Program (No. 2017YQ015) and the Scientific Research Program of the Shanghai Science and Technology Committee (No. 15411963200). We are very grateful to the members in our laboratory.

\section{Author details}

${ }^{1}$ Faculty of Anesthesiology, Changhai Hospital, Second Military Medical University, Shanghai 200433, China. ${ }^{2}$ Department of Cell Biology, School of Basic Medicine, Second Military Medical University, Shanghai 200433, China. ${ }^{3}$ School of Life Science, Nanjing University, 210023 Nanjing, Jiangsu Province, China. ${ }^{4}$ State Key Laboratory of Pharmaceutical Biotechnology, Nanjing University, 210023 Nanjing, Jiangsu Province, China

\section{Author contributions}

Jiang Z.Y. and Bo L.L. performed the majority of the experiments and contributed to manuscript preparation. Deng X.M. and Yu X.Y. designed the whole article and prepared the manuscript. Wang C. and Chen T.X. provided important instructions for various techniques and participated in encouraging discussions of the research. Wang C.L. and Meng Y. contributed to some of the experiments and statistical analyses.

\section{Conflict of interest}

The authors declare that they have no conflict of interest.

\section{Publisher's note}

Springer Nature remains neutral with regard to jurisdictional claims in published maps and institutional affiliations.

Supplementary Information accompanies this paper at (https://doi.org/ 10.1038/s41419-018-0838-9).

Received: 19 January 2018 Revised: 22 June 2018 Accepted: 25 June 2018 Published online: 28 August 2018

\section{References}

1. Andries, O. et al. Innate immune response and programmed cell death following carrier-mediated delivery of unmodified mRNA to respiratory cells. J. Control Release 167, 157-166 (2013).

2. Singer, M. et al. The third international consensus definitions for sepsis and septic shock (Sepsis-3). JAMA 315, 801-810 (2016).

3. Canabal, J. M. \& Kramer, D. J. Management of sepsis in patients with liver failure. Curr. Opin. Crit. Care 14, 189-197 (2008).

4. Kramer, L., Jordan, B., Druml, W., Bauer, P. \& Metnitz, P. G. H. Incidence and prognosis of early hepatic dysfunction in critically ill patients - a prospective multicenter study. Crit. Care Med. 35, 1099-1104 (2007).

5. Yan, J., Li, S. \& Li, S. L. The role of the liver in sepsis. Int. Rev. Immunol. 33, 498-510 (2014)

6. Hattori, Y., Hattori, K., Suzuki, T. \& Matsuda, N. Recent advances in the pathophysiology and molecular basis of sepsis-associated organ dysfunction: novel therapeutic implications and challenges. Pharmacol. Ther. 177, 56-66 (2017).

7. van der Poll, T. Future of sepsis therapies. Crit. Care 20, 106 (2016).

8. Zhang, $\mathrm{H}$. et al. GSK-3 beta inhibition attenuates CLP-induced liver injury by reducing inflammation and hepatic cell apoptosis. Mediat. Inflamm. 2014, 629507 (2014).

9. Chen, Y. L. et al. Inhibition of hepatic cells pyroptosis attenuates CLP-induced acute liver injury. Am. J. Transl. Res. 8, 5685-5695 (2016).

10. Victor, V. M., Rocha, M., Esplugues, J. V. \& De la Fuente, M. Role of free radicals in sepsis: antioxidant therapy. Curr. Pharm. Des. 11, 3141-3158 (2005).

11. Andrades, M., Ritter, C., Moreira, J. C. F. \& Dal-Pizzol, F. Oxidative parameters differences during non-lethal and lethal sepsis development. J. Surg. Res. 125, 68-72 (2005).

12. Andrades, M. et al. Antioxidant Treatment Reverses Organ Failure in Rat Model of Sepsis: Role of Antioxidant Enzymes Imbalance, Neutrophil Infiltration, and Oxidative Stress. J. Surg. Res. 167, E307-E313 (2011).

13. Ito, S. et al. GADD34 suppresses lipopolysaccharide-induced sepsis and tissue injury through the regulation of macrophage activation. Cell Death Dis. 7, e2219 (2016).

14. Cho, H. I., Kim, S. J., Choi, J. W. \& Lee, S. M. Genipin alleviates sepsis-induced liver injury by restoring autophagy. Br. J. Pharmacol. 173, 980-991 (2016).

15. Kundu, M. \& Thompson, C. B. Macroautophagy versus mitochondrial autophagy: a question of fate? Cell Death Differ. 12, 1484-1489 (2005).

16. Jiang, Y. et al. Sinomenine hydrochloride protects against polymicrobial sepsis via autophagy. Int. J. Mol. Sci. 16, 2559-2573 (2015).

17. Lin, C. W. et al. T-cell autophagy deficiency increases mortality and suppresses immune responses after sepsis. PLOS ONE 9, e102066 (2014).

18. Ren, C., Zhang, H., Wu, T. T. \& Yao, Y. M. Autophagy: a potential therapeutic target for reversing sepsis-induced immunosuppression. Front. Immunol. 8, 1832 (2017).

19. Hsieh, C. H., Pai, P. Y., Hsueh, H. W., Yuan, S. S. \& Hsieh, Y. C. Complete induction of autophagy is essential for cardioprotection in sepsis. Ann. Surg. 253, 1190-1200 (2011).

20. Lo, S. et al. LC3 over-expression improves survival and attenuates lung injury through increasing autophagosomal clearance in septic mice. Ann. Surg. 257, 352-363 (2013).

21. Howell, G. M. et al. Augmenting autophagy to treat acute kidney injury during endotoxemia in mice. PLOS ONE 8, e69520 (2013).

22. Goll, D. E., Thompson, V. F., Li, H. Q., Wei, W. \& Cong, J. Y. The calpain system. Physiol. Rev. 83, 731-801 (2003)

23. Russo, R. et al. Calpain-mediated cleavage of Beclin-1 and autophagy deregulation following retinal ischemic injury in vivo. Cell Death Dis. 2, e144 (2011).

24. Rodriguez, G. E. V. \& Torriglia, A. Calpain 1 induce lysosomal permeabilization by cleavage of lysosomal associated membrane protein 2. BBA Mol. Cell Res. 1833, 2244-2253 (2013).

25. Zafrani, L. et al. Calpastatin controls polymicrobial sepsis by limiting procoagulant microparticle release. Am. J. Resp. Crit. Care 185, 744-755 (2012).

26. Feng, Y. Y., Zhou, L. H., Sun, X. T. \& Li, Q. Homeodomain-interacting protein kinase 2 (HIPK2): a promising target for anti-cancer therapies. Oncotarget $\mathbf{8}$ 20452-20461 (2017)

27. D'Orazi, G. et al. Homeodomain-interacting protein kinase-2 phosphorylates p53 at Ser 46 and mediates apoptosis. Nat. Cell Biol. 4, 11-19 (2002).

28. Hofmann, T. G. et al. Regulation of p53 activity by its interaction with homeodomain-interacting protein kinase-2. Nat. Cell Biol. 4, 1-10 (2002).

29. Akaike, Y. et al. Homeodomain-interacting protein kinase 2 regulates DNA damage response through interacting with heterochromatin protein 1 gamma. Oncogene 34, 3463-3473 (2015).

30. Al-Beiti, M. A. M. \& Lu, X. Expression of HIPK2 in cervical cancer: correlation with clinicopathology and prognosis. Aust. N Z J. Obstet. Gyn 48, 329-336 (2008).

31. Deshmukh, $\mathrm{H}$. et al. High-resolution, dual-platform aCGH analysis reveals frequent HIPK2 amplification and increased expression in pilocytic astrocytomas. Oncogene 27, 4745-4751 (2008).

32. Imberg-Kazdan, $\mathrm{K}$. et al. A genome-wide RNA interference screen identifies new regulators of androgen receptor function in prostate cancer cells. Genome Res. 23, 581-591 (2013).

33. Schulten, H. J. et al. Microarray expression data identify DCC as a candidate gene for early meningioma progression. PLOS ONE 11, e0153681 (2016).

34. Torrente, L. et al. Crosstalk between NRF2 and HIPK2 shapes cytoprotective responses. Oncogene 36, 6204-6212 (2017). 
35. Kobayashi, E. H. et al. Nrf2 suppresses macrophage inflammatory response by blocking proinflammatory cytokine transcription. Nat. Commun. 7, 11624 (2016).

36. Liu, J., Wu, K. C., Lu, Y. F., Ekuase, E. \& Klaassen, C. D. NRF2 protection against liver injury produced by various hepatotoxicants. Oxid. Med. Cell Longev. 2013, 305861 (2013).

37. Thimmulappa, R. K. et al. Nrf2 is a critical regulator of the innate immune response and survival during experimental sepsis. J. Clin. Invest. 116, 984-995 (2006).

38. Nakasone, M. et al. Preconditioning by low dose LPS prevents subsequent LPS-induced severe liver injury via Nrf2 activation in mice. Yonago. Acta Med. 59, 223-231 (2016).

39. Naidu, S. D. et al. Transcription factors NRF2 and HSF1 have opposing functions in autophagy. Sci. Rep. 7, 11023 (2017).

40. Jiang, T. et al. p62 links autophagy and Nrf2 signaling. Free Radic. Biol. Med. 88, 199-204 (2015).

41. Zhang, Z. et al. Prolonged ethanol treatment enhances lipopolysaccharide/ phorbol myristate acetate-induced tumor necrosis factor-alpha production in human monocytic cells. Alcohol Clin. Exp. Res. 25, 444-449 (2001).

42. Rittirsch, D., Huber-Lang, M. S., Flierl, M. A. \& Ward, P. A. Immunodesign of experimental sepsis by cecal ligation and puncture. Nat. Protoc. 4, 31-36 (2009).

43. Ozturk, E. et al. Propofol and erythropoietin antioxidant properties in rat brain injured tissue. Prog. NeuroPsychopharmacol. Biol. Psychiatry 32, 81-86 (2008).

44. Guo, S. Q., Zhang, Y., Wang, Z. F., Yu, Y. H. \& Wang, G. L. Intraperitoneal gardiquimod protects against hepatotoxicity through inhibition of oxidative stress and inflammation in mice with sepsis. J. Biochem. Mol. Toxicol. 31 https://doi.org/10.1002/jbt.21923 (2017).

45. Tung, M. C. et al. Knockdown of lipocalin-2 suppresses the growth and invasion of prostate cancer cells. Prostate 73, 1281-1290 (2013).

46. Cao, D. et al. Modulation of TNF-alpha mRNA stability by human antigen $R$ and miR181s in sepsis-induced immunoparalysis. EMBO Mol. Med. 7, 140-157 (2015).

47. Klaunig, J. E. et al. Mouse liver cell culture. I. Hepatocyte isolation. In Vitro 17, 913-925 (1981).

48. Zhou, L. K. et al. Cidea promotes hepatic steatosis by sensing dietary fatty acids. Hepatology 56, 95-107 (2012).

49. Tabrizi, S. J. et al. T cell leukemia/lymphoma 1 and galectin-1 regulate survival/ cell death pathways in human naive and $\lg \mathrm{M}(+)$ memory B cells through altering balances in BCl-2 family proteins. J. Immunol. 182, 1490-1499 (2009).

50. Yun, S. et al. Interaction between integrin alpha(5) and PDE4D regulates endothelial inflammatory signalling. Nat. Cell Biol. 18, 1043-1053 (2016).

51. Noda, T. \& Klionsky, D. J. The quantitative Pho8Delta60 assay of nonspecific autophagy. Methods Enzymol. 451, 33-42 (2008).

52. Ganley, I. G., Wong, P. M., Gammoh, N. \& Jiang, X. J. Distinct autophagosomallysosomal fusion mechanism revealed by thapsigargin-induced autophagy arrest. Mol. Cell 42, 731-743 (2011).

53. Yen, Y. T. et al. Enhancing autophagy with activated protein $C$ and rapamycin protects against sepsis-induced acute lung injury. Surgery 153, 689-698 (2013).

54. Wang, B. et al. Resveratrol-enhanced autophagic flux ameliorates myocardial oxidative stress injury in diabetic mice. J. Cell Mol. Med. 18, 1599-1611 (2014)
55. Shi, M. et al. Calpain, Atg5 and Bak play important roles in the crosstalk between apoptosis and autophagy induced by influx of extracellular calcium. Apoptosis 18, 435-451 (2013).

56. Takahashi, W. et al. Kinetics and protective role of autophagy in a mouse cecal ligation and puncture-induced sepsis. Crit. Care. 17, R160 (2013).

57. Tang, Z. et al. Enhanced liver autophagic activity improves survival of septic mice lacking surfactant proteins A and D. Tohoku J. Exp. Med. 231, 127-138 (2013).

58. Watanabe, E. et al. Sepsis induces extensive autophagic vacuolization in hepatocytes: a clinical and laboratory-based study. Lab. Invest. 89, 549-561 (2009).

59. Wan, S. X. et al. Ghrelin protects small intestinal epithelium against sepsisinduced injury by enhancing the autophagy of intestinal epithelial cells. Biomed. Pharmacother. 83, 1315-1320 (2016).

60. Kang, R., Zeh, H. J., Lotze, M. T. \& Tang, D. The Beclin 1 network regulates autophagy and apoptosis. Cell Death Differ. 18, 571-580 (2011).

61. Cutting, A. S. et al. The role of autophagy during group B streptococcus infection of blood-brain barrier endothelium. J. Biol. Chem. 289, 35711-35723 (2014).

62. Diakopoulos, K. N. et al. Impaired autophagy induces chronic atrophic pancreatitis in mice via sex- and nutrition-dependent processes. Gastroenterology $148,626(2015)$

63. Lamoureux, F. et al. Blocked autophagy using lysosomotropic agents sensitizes resistant prostate tumor cells to the novel Akt inhibitor AZD5363. Clin. Cancer Res. 19, 833-844 (2013).

64. $\mathrm{Yu}$, L. et al. Termination of autophagy and reformation of lysosomes regulated by mTOR. Nature 465, 942-U911 (2010).

65. Kirkegaard, K., Taylor, M. P. \& Jackson, W. T. Cellular autophagy: surrender, avoidance and subversion by microorganisms. Nat. Rev. Microbiol. 2, 301-314 (2004).

66. Lamb, C. A., Yoshimori, T. \& Tooze, S. A. The autophagosome: origins unknown, biogenesis complex. Nat. Rev. Mol. Cell Biol. 14, 759-774 (2013).

67. Laufenberg, L. J., Pruznak, A. M., Navaratnarajah, M. \& Lang, C. H. Sepsisinduced changes in amino acid transporters and leucine signaling via mTOR in skeletal muscle. Amino Acids 46, 2787-2798 (2014).

68. Yousefi, S. et al. Calpain-mediated cleavage of Atg5 switches autophagy to apoptosis. Nat. Cell Biol. 8, 1124-U1146 (2006).

69. Das, R. et al. The homeodomain-interacting protein kinase HPK-1 preserves protein homeostasis and longevity through master regulatory control of the HSF-1 chaperone network and TORC1-restricted autophagy in Caenorhabditis elegans. PLoS. Genet. 13, e1007038 (2017).

70. Martin, D. E., Soulard, A. \& Hall, M. N. TOR regulates ribosomal protein gene expression via PKA and the forkhead transcription factor FHL1. Cell 119, 969-979 (2004).

71. Schmelzle, T., Beck, T., Martin, D. E. \& Hall, M. N. Activation of the RAS/cyclic AMP pathway suppresses a TOR deficiency in yeast. Mol. Cell Biol. 24, 338-351 (2004).

72. Lewis, J. R. \& Mohanty, S. R. Nonalcoholic fatty liver disease: a review and update. Dig. Dis. Sci. 55, 560-578 (2010).

73. Ahmed, M. H. \& Byrne, C. D. Current treatment of non-alcoholic fatty liver disease. Diabetes Obes. Metab. 11, 188-195 (2009).

74. Dietrich, P. \& Hellerbrand, C. Non-alcoholic fatty liver disease, obesity and the metabolic syndrome. Best Pract. Res. Clin. Gastroenterol. 28, 637-653 (2014). 